\title{
Characterisation of children's asthma status by ICD-9 code and criteria-based medical record review
}

\author{
*Young Juhna, Amiinah Kung ${ }^{b}$, Robert Voigta, Shirley Johnson ${ }^{a}$ \\ a Department of Community Pediatric \& Adolescent Medicine, Mayo Clinic, Minnesota, USA \\ ${ }^{\mathrm{b}}$ Department of Allergy and Immunology, University of California, Los Angeles, California, USA
}

Received 11th May 2010; revised 7th August 2010; accepted 23rd September 2010; online 10th November 2010

\begin{abstract}
Objective: To characterise the relationship between ICD code-based (i.e. physician diagnosis-based) and criteria-based asthma ascertainment.

Methods: We compared identification of children with asthma between criteria-based medical record review for asthma ascertainment and an ICD-9 code-based approach. We determined the agreement rate and validity index of ICD code-based asthma ascertainment using asthma status by medical record review as a gold standard.

Results: Of the 115 study subjects, the agreement between medical record review and ICD-9 coding was $81.6 \%$ with a kappa value of 0.28 ( $P<0.0001)$. Sensitivity, specificity, positive and negative predictive values for ICD-9 code were $24.0 \%, 97.8 \%, 75.0 \%$, and $82.0 \%$, respectively, using criteria for asthma by medical record review as gold standard.

Conclusions: ICD code-based asthma ascertainment appears to under-identify children with asthma compared to criteria-based medical record review. ICD codes may be useful for etiologic research but may not be suitable for surveillance of asthma epidemiology.

(C) 2011 Primary Care Respiratory Society UK. All rights reserved.

Y Juhn et al. Prim Care Respir J 2011; 20(1): 79-83

doi:10.4104/pcrj.2010.00076
\end{abstract}

Keywords asthma, ICD code, diagnosis, validity, medical record review, agreement

See linked editorial by Kalra and Fernando on page 4

\section{Introduction}

There is no consensus on the diagnosis of asthma, and thus diagnosing asthma in young children is often difficult and variable. In clinical settings, the diagnosis of childhood asthma is often delayed, preventing children with asthma from receiving appropriate medical treatment and health care services. ${ }^{1,2}$ Similarly, no standard and consistent methods for ascertaining asthma status have been used for asthma research. Various methods for ascertaining asthma status have been applied in epidemiologic research. We have previously reported on the relationship between parental report of the asthma status of their children and asthma status by medical record review based on predetermined criteria for asthma. ${ }^{3}$ We found that there was a significant discrepancy in ascertainment of asthma between parental report and the criteria-based medical record review (the specific proportionate agreement for positive rating was $49 \%$ and the specific proportionate agreement for negative rating was $89 \%$ ).

Ascertainment of asthma by ICD code is a popular method in large-scale epidemiologic studies. ${ }^{4 \cdot 6}$ For example, Talbot et al. reported an increased risk of invasive pneumococcal diseases (IPD) among asthmatics in a large-scale case-control study that used ICD code for asthma to ascertain the asthma status of IPD cases and controls. This study was part of the evidence that led the Advisory Committee on Immunization Practices to change the pneumococcal vaccine policy for adults to include asthma in the pneumococcal vaccine eligible conditions. However, our recent study showed that a significant proportion of children who met criteria for asthma had a delay in the diagnosis of asthma for up to 3.3 years.' Thus, ascertaining asthma status based on ICD code - i.e. physician diagnosis of asthma - may underestimate the prevalence of asthma.

\footnotetext{
*Corresponding author: Dr Young J Juhn, Department of Community Pediatric \& Adolescent Medicine, Mayo Clinic, 200 First Street SW, Rochester, Minnesota, 55944, USA. Tel: +1 507-284-5243 Fax: +1 507-284-9744 E-mail: juhn.young@mayo.edu
} 
The ICD code is understood to be reflective of a physiciandiagnosed medical condition, but a previous study demonstrated a lack of asthma diagnoses in school-aged children despite clinical symptoms clearly demonstrated in the medical record.7 A recent population-based survey by Bisgaard and Szefler showed that a significant proportion of preschool children (32\%) experience recurrent clinicallysignificant asthma-like symptoms (cough, wheezing, and breathlessness) in European countries and the USA based on 2,700 paediatric subjects. ${ }^{2}$ In this study, only $20 \%$ of the study population were diagnosed with asthma. The authors concluded that "there is a striking lack of international consensus on diagnosis and treatment for asthma and this uncontrolled morbidity highlights a significant unmet clinical need in preschool children."

Therefore, use of ICD codes may substantially underestimate the true prevalence of asthma within a population. The nature of ICD codes in ascertaining asthma status in relation to other methods, such as criteria-based medical record review, has not been well studied. To address this issue, we assessed the concordance between asthma status by ICD-9 code for asthma and our criteria-based asthma status by medical record review.

\section{Methods}

\section{Study design and setting}

This study was designed as a cross-sectional survey study nested in a retrospective cohort study. Rochester, Minnesota, is an excellent setting to conduct an epidemiologic study utilising medical records such as this one, since medical care is virtually self-contained within the community and a unified medical record system has been maintained among the two medical centres serving the community for the past 90 years. This dossier-type medical record system contains all inpatient and outpatient data since 1935 in an automated form. ${ }^{8}$

\section{Study subjects}

This study was approved by the Institutional Review Board for Human Subject Research at the Mayo Clinic and Olmsted Medical Center. The study subjects of the original study were children under four years of age who were enrolled in the Mayo Clinic sick child care program, and their parents. ${ }^{3,9}$ They participated in the original study that assessed factors associated with parents' care-seeking behaviour for mild acute illnesses of young children. Parents (i.e. Mayo Clinic employees) who take their children to the sick child care program are allowed to request on-site medical evaluations for their children with mild acute illnesses. Thus, children with or without medical evaluations at the sick child care program were eligible for the original study. This sampling approach had an advantage over clinic-based sampling, which is limited to subjects seeking medical evaluations. Exclusion criteria of the original study included children who were turned away or excluded by the sick child care program due to lack of availability for care and those being seen for follow-up care/post-surgery/trauma care.

\section{Ascertainment of Asthma status by ICD code}

All Hospital Adoption of International Classification of Disease Second Edition (HICD) codes of 493 for the study subjects during their first four years of life were identified and confirmed by medical record review. The ICD-9 codes for asthma (493.0-9) of the study subjects were initially retrieved from the Rochester Epidemiology Project database, a unified medical record system for all Olmsted County, Minnesota, residents, using a computer program. We confirmed that all children with a physician diagnosis of asthma had ICD-9 codes for asthma.

\section{Asthma status by medical record review}

We conducted comprehensive medical record reviews for the study subjects to determine their asthma status by applying predetermined criteria for asthma. These criteria are detailed in Table 1. The criteria for asthma based on medical record review were developed during a previous study by Yunginger et $a l .{ }^{10}$ In the original study, to assess the reliability of the criteria, random samples of records were reviewed by different nurse abstractors and analysed for inter-observer reliability and agreement rates between abstractors, and a high degree of concordance was found..$^{11}$ Numerous previous studies on asthma epidemiology research have used these criteria to define asthma. ${ }^{12-21}$ Briefly, for criterion 1, we reviewed the entire medical record to identify a history of cough with wheezing and/or shortness of breath documented by physicians OR documented wheezing episodes on examination with cough and/or shortness of

\section{Table 1. Asthma criteria}

Definite asthma if a physician had made a diagnosis of asthma and the presence of two of the following 3 conditions or if each of the following 3 conditions were present. Probable asthma if only 2 of the following 3 conditions were present or a physician had made a diagnosis of asthma with either none or only one of the following three conditions:

1. History of cough with dyspnoea and/or wheezing, OR history of cough and/or dyspnoea plus wheezing on exam,

2. Substantial variability in symptoms from time to time or periods of weeks or more when symptoms were absent, and

3. Two or more of the following:

- Sleep disturbance by nocturnal cough and wheeze

- Nonsmoker (14 yr or older)

- Nasal polyps

- Blood eosinophilia higher than 300/uL

- Positive wheal and flare skin tests OR Elevated serum IgE

- History of hay fever or infantile eczema OR Cough, dyspnoea, and wheezing regularly on exposure to an antigen

- Pulmonary function tests showing one $\mathrm{FEV}_{1}$ or $\mathrm{FVC}<70 \%$ predicted and another with at least $20 \%$ improvement to an $\mathrm{FEV}_{1}$ of higher than $70 \%$ predicted OR methacholine challenge test showing $\geq 20 \%$ decline in $\mathrm{FEV}_{1}$

- Favourable clinical response to bronchodilator 
breath. Criterion 2 was met when a history of the constellation of the above asthma symptoms or signs had occurred at least twice or more within three-year periods of the first episode, with the documented interim periods without asthma symptoms. When two of eight items of the third criterion were documented in the medical records, we considered the third criterion to be met.

\section{Data analysis}

We summarised the prevalence of asthma by ICD-9 code and criteria-based medical record review alone. To analyse interobserver reliability on asthma status between ICD-9 code and criteria-based medical record review, we calculated Cohen's unweighted kappa index. Cohen's kappa is based on the difference between the observed proportion of subjects upon whom the two informants agree and the proportion expected by chance, given the marginal distributions. To understand the kappa index better, we calculated the specific proportionate agreement for positive (i.e. both ICD-9 code and medical record review suggested asthma) and negative (i.e. both ICD-9 code and medical record review suggested not asthma) ratings in asthma status of the subjects between ICD-9 code and medical record review. We measured sensitivity, specificity, positive predictive value, and negative predictive value using the asthma criteria based on medical record review as the gold standard. To determine the construct validity of each asthma ascertainment method, data were fitted to a logistic regression model, and the association between known crisk factors for asthma and asthma status by ICD-9 code vs. the criteria-based medical record review was assessed. The associations were summarised by calculating odds ratios (OR) and corresponding 95\% confidence intervals $(\mathrm{Cl})$.

\section{Results}

\section{Study cohort}

A convenience sample of 115 parents and their 115 children participated in the original study. Of the 115 parents, 105 (93\%) were female (i.e. mothers) and 90\% were Caucasians (see Table 2). The mean age of the parents was 32.9 years (standard deviation, SD: 5.3 years). Of the 115 parents, 5 (4.4\%) had a high school diploma, 33 (28.7\%) had some college education, 42 (36.5\%) had college degrees, and 35 (30.4\%) had professional or graduate degrees. Of the 115 children who participated in the original study, $84 \%$ were reported to be Caucasians and 49\% were female. The mean age was 2.0 years (SD, 1.03).

\section{Prevalence and agreement of asthma by ICD code and} medical record review

Of the 115 subjects, there was a difference in asthma prevalence between those who were identified by medical record review, with 26 subjects who were identified with asthma by the criteria-based medical record review $(22.6 \%$,

\begin{tabular}{|c|c|c|}
\hline & Child & Parents \\
\hline Number (n) & 115 & 115 \\
\hline Age $(y r$, mean $\pm S D)$ & $1.99( \pm 1.03)$ & $32.93( \pm 5.25)$ \\
\hline Sex, $r$ & & \\
\hline $\begin{array}{r}\text { Male } \\
\text { Female }\end{array}$ & $\begin{array}{l}60(52.2) \\
55(47.8)\end{array}$ & $\begin{array}{c}8(7.2) \\
105(92.8)\end{array}$ \\
\hline $\begin{array}{r}\text { White } \\
\text { African American } \\
\text { Hispanic } \\
\text { Asian } \\
\text { Mixed } \\
\text { Others }\end{array}$ & $\begin{array}{c}97(84.4) \\
2(1.7) \\
3(2.6) \\
8(6.9) \\
5(4.4) \\
0\end{array}$ & $\begin{array}{c}104(90.4) \\
0 \\
2(1.7) \\
7(6.1) \\
1(0.9) \\
1(0.9)\end{array}$ \\
\hline $\begin{array}{r}\text { Parents' educational status, } \mathrm{n}(\%) \\
\text { High school diploma/GED } \\
\text { Vocational school } \\
\text { College } \\
\text { Professional or graduate }\end{array}$ & $\begin{array}{l}- \\
- \\
- \\
-\end{array}$ & $\begin{array}{c}5(4.4) \\
33(28.7) \\
42(36.5) \\
35(30.4)\end{array}$ \\
\hline $\begin{array}{r}\text { Asthma prevalence, } \mathrm{n}(\% \text { and } 95 \% \\
\text { ICD code } \\
\text { Criteria-based medical record review } \\
\text { Both }\end{array}$ & $\begin{array}{l}\text { I) } \\
9(7.8,95 \% \\
\text { Cl: } 3.6-14.3) \\
26(22.6,95 \% \\
\text { Cl: } 15.3-31.3) \\
6(5.2,95 \% \\
C l: 2-11)\end{array}$ & - \\
\hline
\end{tabular}

Cl: confidence interval

95\% Cl: 15.3-31.3) compared to only 9 subjects by ICD-9 code (7.8\%, 95\% Cl: 3.6-14.3) ( $p<0.001)$. These prevalence figures can be compared with the prevalence of asthma determined by parental report $(15 \%, 95 \% \mathrm{Cl}: 7.5-20.5)$. The overall agreement on asthma status between ICD-9 code and medical record review was $81.6 \%$, but with a $\kappa$ value of only $0.28(P<0.0001)$. This discrepancy between $\kappa$ value and agreement rate occurs due to unequal distribution of events captured by two comparison groups. Thus, to examine the relationship further, the specific proportionate agreement was calculated for both positive (i.e. both ICD-9 code and medical record indicated positive asthma status) and negative (i.e. both ICD-9 code and medical record indicated negative asthma status) ratings. With a positive specific proportionate agreement at $89 \%$ but a negative specific proportionate agreement of only $36 \%$, this indicates that a positive diagnosis of asthma by ICD-9 code is strongly associated with a true diagnosis by medical record, but the converse is not true. The sensitivity, specificity, positive and negative predictive values for ICD-9 code by medical record review were $24.0 \%, 97.8 \%, 75.0 \%$, and $82.0 \%$, respectively.

Factors associated with asthma status by ICD code or medical record review

The results of univariate analyses for the association between risk factors and asthma status by ICD-9 code vs. the criteria- 
Table 3. Association between known risk factors for asthma and asthma status by different ascertainment methods for asthma.

\begin{tabular}{|c|c|c|c|c|c|}
\hline & & \multicolumn{2}{|c|}{ Medical record } & \multicolumn{2}{|c|}{ ICD code } \\
\hline & & Odds ratio $(95 \% \mathrm{Cl})$ & $\mathrm{p}$-value & Odds ratio $(\mathrm{Cl})$ & p-value \\
\hline Gender & $\begin{array}{r}\text { Male } \\
\text { Female }\end{array}$ & $\begin{array}{c}\text { reference } \\
0.40(0.16,1.01)\end{array}$ & 0.05 & $\begin{array}{c}\text { reference } \\
0.92(0.23,3.54)\end{array}$ & 0.91 \\
\hline History of atopic conditions & $\begin{array}{l}\text { No } \\
\text { Yes }\end{array}$ & $\begin{array}{c}\text { reference } \\
5.36(1.81,15.89)\end{array}$ & 0.002 & $\begin{array}{c}\text { reference } \\
3.94(0.85,18.35)\end{array}$ & 0.08 \\
\hline Family history of asthma & $\begin{array}{l}\text { No } \\
\text { Yes }\end{array}$ & $\begin{array}{c}\text { reference } \\
2.00(0.77,5.23)\end{array}$ & 0.157 & $\begin{array}{c}\text { reference } \\
4.63(1.49,14.36)\end{array}$ & 0.008 \\
\hline History of wheezing & $\begin{array}{l}\text { No } \\
\text { Yes }\end{array}$ & $\begin{array}{c}\text { reference } \\
9.15(3.13,26.76)\end{array}$ & $<0.001$ & $\begin{array}{c}\text { reference } \\
13(1.56,107.85)\end{array}$ & 0.018 \\
\hline
\end{tabular}

based medical record review are summarised in Table 3. According to these results, significant factors associated with asthma status by ICD-9 code were family history of asthma and history of wheezing. Significant factors associated with asthma status by criteria-based medical record review included male gender, the child's history of atopy, and a history of wheezing. Factors such as socioeconomic status, tobacco exposure, and breastfeeding, showed no correlation with either of the asthma ascertainment methods.

\section{Discussion}

The diagnosis of illnesses by ICD code is useful for quick categorisation and organisation of patients within a medical institution. However, the true validity of these diagnoses has been questioned for other diseases..22,23 For asthma, the difficulty of diagnosis in young children would certainly bring into question the accuracy of ICD coding for these patients. Although our findings are based on a small sample size, this study confirms our suspicions: a diagnosis of asthma by ICD code is likely to represent a child with a higher likelihood of childhood asthma, but the lack of a diagnosis does not necessarily indicate lack of disease.

Our study demonstrates that determination of asthma status by ICD-9 code does show some validity. The agreement between ICD-9 code and the criteria-based medical record review is strong in that both are positive for asthma. This high degree of concordance indicates that using ICD codes is a useful method for identifying children who have a higher likelihood of true asthma. This is also supported in our analysis of the various risk factors for asthma in relationship to each ascertainment method. Well-established risk factors such as atopy, family history of asthma, and history of wheezing all show a positive correlation with both ICD code and medical record review. These findings support the construct validity of both ascertainment methods, and that ICD codes in particular can be useful for etiologic research in asthma.

However, caution must be used in interpreting the use of
ICD codes as the sole basis of asthma ascertainment in research studies. The number of asthmatic patients identified by ICD-9 code (9 patients) was significantly less than those identified by the criteria-based medical record review (26 patients), indicating poor representation of the prevalence of disease (7.8\% versus $22.6 \%$, respectively). In addition, the negative specific proportionate agreement is low, indicating low agreement rates between negative diagnosis by ICD-9 and negative findings in the medical record. These findings not only have ramifications for etiologic research, but may indicate delayed treatment of asthma in young children. Delay in diagnosis of asthma in young children may lead to adverse health outcomes. Undiagnosed children with asthma are much less likely to receive appropriate treatment and are at risk for recurrence of symptoms affecting their quality of life. ${ }^{24}$

The cause of this dissociation in asthma ascertainment by both methods may be physician reluctance to label a patient with asthma. ICD-9 codes assigned to patients have farreaching ramifications in the era of managed health care, ${ }^{24}$ where a patient's health status may be affected by a diagnosis of asthma documented in medical records. Therefore, a physician may defer adding a diagnosis of asthma as an ICD code and may choose a less negatively-charged term such as 'bronchospasm' or 'wheezing'. However, we believe that the primary reason for a delay in asthma diagnosis may be the lack of an international consensus on asthma diagnosis as suggested by Bisgaard and Szefler. ${ }^{2}$

A potential limitation of our study is that our criteria for probable asthma included a physician diagnosis of asthma. A significant proportion of the subjects $(17 / 26,65 \%)$ had asthma without positive ICD coding for asthma, notably without a single asthma case solely based on physician diagnosis without any history or evaluation suggesting asthma. Therefore, although the physician diagnosis of asthma is a subset of asthma cases determined by our criteria, in actual medical record review, most (if not all) asthma cases based on a physician diagnosis of asthma meet the criteria for definite asthma since they have full-blown 
symptoms and histories suggesting asthma. This is one of the main points of our paper - that ascertainment of asthma by physician diagnosis alone underestimates the prevalence of asthma in an epidemiologic study.

Another limitation is the small sample size. However, we accomplished our study goals with the given sample size, and this concern becomes more relevant if our study did not find any significant association (i.e. type II error). As our study subjects were predominantly Caucasian (97\%), the results of this study may not be generalisable to other study settings. Also, we did not address the characteristics of the physicians who were involved in making asthma diagnoses in relation to our study results. In addition, given the young age of our cohort, these findings may not hold true in older populations or adults. However, a study setting such as ours allows for analysis with strict criteria and serves as an important starting point for better understanding of the utility of using ICD coding in asthma research for children. Consequently, we hope to draw attention to an area that requires further investigation.

In conclusion, ICD code-based ascertainment of asthma seems to under-identify children with asthma compared to the criteria-based medical record review. ICD codes may be useful for etiologic research in asthma but may not be suitable for monitoring trends of asthma or studying asthma epidemiology.

\section{Acknowledgement}

We are grateful to Angela Bovia and the staff of the Pediatric Asthma Epidemiology Research Unit for their administrative and research assistance. The study was funded by a Scholarly Clinician Award from the Mayo Foundation.

\section{Conflict of interest declarations}

The study investigators have nothing to disclose that poses a conflict of interest.

\section{References}

1. Molis W, Bagnieski S, Weaver A, Jacobson R, Juhn Y. Timeliness of Diagnosis of Asthma in Children and its Predictors. Allergy 2008;63:1529-35. http://dx.doi.org/10.1111/j.1398-9995.2008.01749.x

2. Bisgaard H, Szefler S. Prevalence of Asthma-Like Symptoms in Young Children. Pediatric Pulmonolgy 2007;42:723-8. http://dx.doi.org/10.1002/ppul.20644

3. Yoo KH, Johnson SK, Voigt RG, Campeau LJ, Yawn BP, Juhn YJ. Characterization of Asthma Status by Parent Report and Medical Record Review. I Allergy and Clinical Immunology 2007;120:1468-9. http://dx.doi.org/10.1016/j.jaci.2007.09.008

4. Talbot T, Hartert, TV, Arbogast, et al. Asthma as a Risk Factor for Invasive Pneumococcal Disease. N Engl J Med 2005;352:2082-90. http://dx.doi.org/10.1056/NEJMoa044113

5. Johnston SL, Pattemore PK, Sanderson G, et al. The relationship between upper respiratory infections and hospital admissions for asthma: a time-trend analysis. Am J Resp Crit Care Med 1996;154(3 Pt 1):654-60.

6. Aylin P, Bottle A, Wakefield J, Jarup L, Elliott P. Proximity to coke works and hospital admissions for respiratory and cardiovascular disease in England and Wales.[comment]. Thorax 2001;56(3):228-33. http://dx.doi.org/10.1136/ thorax.56.3.228

7. Joseph C, Foxman B, Leickly F, Peterson E, Ownby D. Prevalence of possible undiagnosed asthma and associated morbidity among urban schoolchildren. The Journal of Pediatrics 1996;129(5):735-42. http://dx.doi.org/10.1016/S00223476(96)70158-0

8. Kurland L, Molgaard CA. The patient record in Epidemiology. Scientific American 1981;245:54-63. http://dx.doi.org/10.1038/scientificamerican1081-54.

9. Voigt RG, Johnson SK, Mellon MW, et al. Why Parents Seek Medical Care for Their Chidren with Mild Acute Illnesses. Clinical Pediatrics 2008;47:244-51. http://dx.doi.org/10.1177/0009922807308254

10. Yunginger J, Reed CE, O'Connell EJ, Melton J, O'Fallon WM, Silverstein MD. A Community-based Study of the Epidemiology of Asthma: Incidence Rates, 1964-1983. Am Rev Respir Dis 1992;146:888-94.

11. Beard M, Yunginger JW, Reed CE, O'Connell EJ, Silverstein MD. Interobserver Variability in Medical Record Review: An Epidemiological Study of Asthma. J Clin Epidemiol 1992;45(9):1013-20. http://dx.doi.org/10.1016/08954356(92)90117-6

12. Juhn YJ, Weaver A, Katusic S, Yunginger J. Mode of delivery at birth and development of asthma: a population-based cohort study. I Allergy Clin Immunol 2005;116(3):510-16. http://dx.doi.org/10.1016/j.jaci.2005.05.043

13. Juhn YJ, Sauver JS, Katusic S, Vargas D, Weaver A, Yunginger J. The influence of neighborhood environment on the incidence of childhood asthma: a multilevel approach. Social Science \& Medicine 2005;60(11):2453-64. http://dx.doi.org/10.1016/j.socscimed.2004.11.034

14. Yawn BP, Yunginger JW, Wollan PC, Reed CE, Silverstein MD, Harris AG. Allergic rhinitis in Rochester, Minnesota residents with asthma: frequency and impact on health care charges. J Allergy Clin Immunol 1999;103(1 Pt 1):54-9. http://dx.doi.org/10.1016/S0091-6749(99)70525-7

15. Yunginger JW, Reed CE, O'Connell EJ, Melton LJ, 3rd, O'Fallon WM, Silverstein MD. A community-based study of the epidemiology of asthma. Incidence rates, 1964-1983.[see comment]. American Review of Respiratory Disease 1992; 146(4):888-94.

16. Hunt LW, Jr., Silverstein MD, Reed CE, O'Connell EJ, O'Fallon WM, Yunginger $J W$. Accuracy of the death certificate in a population-based study of asthmatic patients.[see comment]. JAMA 1993;269(15):1947-52.

17. Beard CM, Yunginger JW, Reed CE, O'Connell EJ, Silverstein MD. Interobserver variability in medical record review: an epidemiological study of asthma. J Clin Epidemio/1992;45(9):1013-20. http://dx.doi.org/10.1016/0895-4356(92)90117-6

18. Bauer BA, Reed CE, Yunginger JW, Wollan PC, Silverstein MD. Incidence and outcomes of asthma in the elderly. A population-based study in Rochester, Minnesota.[see comment]. Chest 997;111(2):303-10.

19. Silverstein $M D$, Yunginger JW, Reed $C E$, et al. Attained adult height after childhood asthma: effect of glucocorticoid therapy. I Allergy Clin Immunol 1997;99(4):466-74. http://dx.doi.org/10.1016/S0091-6749(97)70072-1

20. Juhn YJ, Kita $H$, Lee $L A$, et al. Childhood asthma and measles vaccine response. Annals of Allergy, Asthma, \& Immunology 2006;97(4):469-76. http://dx.doi.org/10.1016/S1081-1206(10)60937-4

21. Juhn YJ, Kita H, Lee LA, et al. Asthma and Human Lymphocyte Antigens Type. Tissue Antigens 2007;69:38-49. http://dx.doi.org/10.1111/j.1399-0039.2006. 00719.x

22. Schneider A, Gantner L, Maag I, Borst MM, Wensing M, Szecsenyi J. Are ICD10 codes appropriate for performance assessment in asthma and COPD in general practice? Results of a cross sectional observational study. BMC Health Services Research 2005;5(1):11. http://dx.doi.org/10.1186/1472-6963-5-11

23. Lopushinsky SR, Covarrubia KA, Rabeneck L, Austin PC, Urbach DR. Accuracy of administrative health data for the diagnosis of upper gastrointestinal diseases. Surgical Endoscopy 2007;21(10):1733-7. http://dx.doi.org/10.1007/ s00464-006-9136-1

24. O'Malley KJ, Cook KF, Price MD, Wildes KR, Hurdle JF, Ashton CM. Measuring diagnoses: ICD code accuracy. Health Services Research 2005;40(5 Pt 2):1620-39. http://dx.doi.org/10.1111/j.1475-6773.2005.00444.x 